\title{
Milk fat composition modifies the texture and appearance of Cantal-type cheeses but not their flavor
}

\author{
Marie Frétin, ${ }^{1,2}$ Bruno Martin, ${ }^{1}$ Solange Buchin, ${ }^{3}$ Béatrice Desserre, ${ }^{2}$ René Lavigne, ${ }^{2}$ Emilie Tixier, ${ }^{1}$ \\ Carole Cirié, ${ }^{4}$ Cécile Bord, ${ }^{2,5}$ Marie-Christine Montel, ${ }^{2}$ Céline Delbès, ${ }^{2}$ and Anne Ferlay ${ }^{1 *}$ \\ ${ }^{4}$ Université Clermont Auvergne, INRA, UE 1414 Herbipôle, F-63122 Saint-Genès-Champanelle, France \\ ${ }^{5}$ VetAgroSup, F-63270 Lempdes, France
}

\section{ABSTRACT}

Although the effects of cow diet on cheese sensory properties have been well documented, the putative interactions between the biochemical and microbial milk components and their respective roles in the development of the sensory properties of cheeses have yet to be explored in depth. The aim of this study was to evaluate the specific contribution of milk fat composition to the formation of cheese sensory properties. Two creams with different fat compositions were obtained from cows fed either pasture or maize silage. Cheeses were manufactured from the same skim milk (identical chemical and microbial composition) with either the pasture- or maize silage-origin pasteurized cream added. The gross composition and microbial composition of milks did not vary with cream origin. In milks and cheeses, the fatty acid (FA) profiles were modified by the origin of the cream. The concentrations of C18:0 and unsaturated FA such as cis-9 C18:1, trans-11 C18:1, C18:3n-3, total conjugated linoleic acids, and mono- and polyunsaturated FA were higher in milks and cheeses with the pasture-origin cream than in those with the maizeorigin cream. In contrast, the maize milks and cheeses had higher concentrations of short- and medium-chain saturated FA, C16:0, and C18:2n-6. The level of lipolysis was $11 \%$ in the cheese rind and only $0.30 \%$ in the cheese core. The rind of pasture cheeses had a higher concentration of free $\mathrm{C} 18: 0$ and $\mathrm{C} 18: 3 \mathrm{n}-3$ and a lower concentration of free C14:0 and free C16:0 than the rind of maize cheeses. The levels of major microbial groups were similar in pasture and maize cheeses at different stages of ripening. The pasture cheeses had a more elastic and creamier texture, a yellower color, and a thinner rind than the maize cheeses, but the odor

Received August 10, 2018.

Accepted October 29, 2018.

*Corresponding author: anne.ferlay@inra.fr and aroma of cheeses were not affected by the origin of the cream, despite a few modifications in the balance of volatile compounds from FA catabolism. Based on these results, we conclude that milk fat composition modulated by cow diet had a direct role in the texture of the cheese but no effect on flavor. The high degree of lipolysis in cheese rind, along with the higher concentration of long-chain unsaturated free FA in pasture cheeses may be responsible for antimicrobial activity, which could explain differences in the appearance of cheese rind.

Key words: milk fatty acids, cheese flavor, rind appearance, microbial group

\section{INTRODUCTION}

The sensory quality of cheeses results from interactions between microbial activity and the biochemical composition of the raw milk throughout ripening. Several studies in recent years have examined the effect of cow diets on cheese sensory properties. The effects of forage type (e.g., grazed or conserved grass vs. maize silage) are well known (Martin et al., 2005). Pasturederived cheeses develop specific sensory features. These cheeses have a thinner rind, a yellower color, a smoother texture, and a more diverse and intense flavor than maize silage-derived cheeses. These color and texture features have been attributed specifically to the milk fat composition, which is much richer in unsaturated fatty acids (FA) and carotenoids when cows are fed fresh grass (Martin et al., 2005). The rind appearance of cheeses is mainly linked to the rind microbiota, in particular to microorganisms deliberately inoculated. Some researchers suggest that the decrease in fat cohesion of pasture-derived cheeses could lead to a more pronounced oiling-off on the cheese rind, creating a less favorable environment for the development of the mold Sporendonema casei, which gives Cantal cheese rind its typical appearance (Coulon et al., 2004; Coppa et al., 
2011) or for the development of species of the Mucor genus on the rind of Saint-Nectaire cheeses (Lerch et al., 2015). The stronger and more diversified flavor of cheeses from milk of pastured cows is still far from understood. Cheese flavor formation relies on the fermentation of sugars and organic acids, the catabolism of AA released by proteolysis, and the release of FA by lipolysis and their subsequent oxidation (McSweeney and Sousa, 2000; Marilley and Casey, 2004). These metabolic pathways involve both microbial enzymes and enzymes naturally present in raw milk (e.g., lipoprotein lipase, plasmin). The effects of cow diet on cheese flavor formation could be closely related to activities of cheese microbiota during ripening because these effects are reduced when milk is pasteurized (Verdier-Metz et al., 2002).

The effect of adding different microbial communities to the same pasteurized or microfiltered milk on the sensory characteristics of cheeses has been evaluated. Callon et al. (2005) and Demarigny et al. (1997) showed that the sensory properties of Salers-type and Gruyère-type cheeses, respectively, may vary according to the composition of the microbial communities inoculated. Recent studies have shown that the microbial communities of cow teat skin can be modified by cow diets (Verdier-Metz et al., 2012; Frétin et al., 2018). However, the effect of cow diets on the microbiota of raw milk is not well understood. The cow diet constitutes a natural way to sharply and rapidly modulate milk fat composition (Ferlay et al., 2017). Grazed grass generally enhances the milk concentrations of cis-9 C18:1 and PUFA, mainly C18:3n-3 and cis-9,trans-11 CLA, and it decreases the concentration of C12:0 to C16:0 compared with a maize silage diet (Chilliard et al., 2007; Ferlay et al., 2017). We can hypothesize that some milk antimicrobial compounds such as free FA may interact with the cheese microbiota (Nieman, 1954; Kabara, 1984) and could be responsible for the effects of diets on the sensory properties of cheeses. To our knowledge, only Buchin et al. (1998) have investigated the effect of milk fat composition on microbial levels in cheese. Those authors compared uncooked, pressed Morbier cheeses manufactured with the same milk added with pasteurized cream obtained from cows fed either pasture or hay. In these conditions, the levels of the major microbial groups were not modified by the milk fat composition in cheeses. Nevertheless, the diets compared in that study were very similar.

Overall, we hypothesize that milk fat composition, determined by the cow diet, is involved in the development of cheese sensory characteristics, either directly or by driving microbial populations in cheese. Independently of the raw milk microbiota that can vary according to cow diet (Verdier-Metz et al., 2002), our aim was to determine the specific influence of milk fat composition on the sensory properties of uncooked, pressed Cantal-type cheeses. To rule out diet-related variations for cheese microbiota composition, we manufactured cheeses made from the same skim milk (identical chemical and microbial composition) and 2 pasteurized creams with different fat compositions, obtained from cows either grazing pasture or fed a maize silage-based diet.

\section{MATERIALS AND METHODS}

\section{Experimental Design}

The experiment was conducted at the experimental farm of Marcenat (INRA, UE 1414, France) in an upland mountainous area of central France $\left(45^{\circ} 18^{\prime} 21^{\prime \prime} \mathrm{N}\right.$, $2^{\circ} 50^{\prime} 13^{\prime \prime} \mathrm{E}$, altitude 1,135-1,215 m). Dairy cows were divided into 2 groups and received different diets. One group (pasture, $\mathbf{P}$ ) of 27 cows (13 Montbéliarde and 14 Holstein) grazed mountain grassland regrowths. The average botanical composition of the grasslands (expressed in \% of the species identified) was $69 \%$ grasses, $10 \%$ legumes, and $21 \%$ forbs. Cows were supplemented daily with an average of $1.4 \mathrm{~kg}(\mathrm{DM})$ of concentrate and $0.2 \mathrm{~kg}$ of mineral and vitamin premix. The other group (maize silage, $\mathbf{M}$ ) of 12 cows (6 Montbéliarde and 6 Holstein) was kept indoors and fed daily a diet composed of $15 \mathrm{~kg}$ DM of maize silage, $2.5 \mathrm{~kg}$ DM of straw, and $5.6 \mathrm{~kg} \mathrm{DM}$ of concentrate distributed twice daily (forage to concentrate ratio: 75.8:24.2). The animals were allocated to these 2 groups based on parity (41 and $42 \%$ of primiparous cows in $\mathrm{P}$ and $\mathrm{M}$ groups, respectively) and lactation stage (228 \pm 121 and $223 \pm$ 59 DIM in $\mathrm{P}$ and $\mathrm{M}$ groups, respectively). Cows were milked with the same milking machine at 0630 and 1630 h. All cows on pasture received a sterile $85 \%$ glycerol solution dipped on the teats following each milking.

\section{Cheesemaking}

Cheeses were made over a period of 2 consecutive weeks in October 2014. The morning milk from each group of cows was cooled at $4^{\circ} \mathrm{C}$, pooled with the following evening milk, and stored at $4^{\circ} \mathrm{C}$ overnight before being transported on the morning of each cheesemaking. Milk from both $\mathrm{P}$ and $\mathrm{M}$ groups was skimmed, and each cream was pasteurized at $70^{\circ} \mathrm{C}$ for $30 \mathrm{~min}$. The $\mathrm{P}$ skim milk was used for all cheese batches. One-half of the skim milk was mixed with the $\mathrm{P}$ pasteurized cream (P-derived cheese milk and cheese) and the other half was mixed with the $\mathrm{M}$ pasteurized cream (M-derived cheese milk and cheese) in a separate vat. The pasteurized cream ( $\mathrm{P}$ or $\mathrm{M})$ was added to obtain the same final 
concentration of fat $(39 \mathrm{~g} / \mathrm{L})$ in each vat. Each day, small Cantal-type cheeses $(10 \mathrm{~kg})$ were manufactured from $110 \mathrm{~L}$ of $\mathrm{P}$ or $\mathrm{M}$ cheese milk concomitantly in 2 vats. Cheesemaking was performed according to Frétin et al. (2017). Briefly, the milk was heated to $33^{\circ} \mathrm{C}$ and inoculated with $0.05 \mathrm{~g}$ of a mesophilic starter culture (Flora Danica Direct, Chr. Hansen, Arpajon, France) with a ripening starter $(1.3 \mathrm{~mL}$ of Monilev and $1.3 \mathrm{~mL}$ of Penbac, Laboratoire Interprofessionnel de Production, Aurillac, France), and $0.33 \mathrm{~g} / \mathrm{kg}$ of a rennet containing $520 \mathrm{mg}$ of active chymosin per liter. Overall, 12 cheeses were produced using either raw (3 consecutive days in wk 1) or pasteurized $\left(78^{\circ} \mathrm{C}, 10 \mathrm{~s} ; 3\right.$ consecutive days in wk 2) P-derived skim milk, with either P- or M-derived pasteurized cream added ( 2 treatments of milk $\times 3$ cheesemaking dates $\times 2$ cream origins). The skim milk was pasteurized in some cheesemakings to determine whether the endogenous milk microbiota may have a particular effect in this context. The cheeses were ripened for 20 wk at $10^{\circ} \mathrm{C}$ and $95 \%$ minimum relative humidity.

\section{Physicochemical Analyses}

Milk. Milk samples from the commingled milk used for cheesemaking were collected in each vat just before the addition of rennet and starter. Milk $\mathrm{pH}$ and urea content were determined in fresh milk as detailed in Martin et al. (2009). Fat, protein, and lactose contents were measured (LIAL, Aurillac, France) by infrared spectrophotometry (Milkoscan 4000, Foss System, Hillerød, Denmark) and, in the same samples, somatic cells were automatically counted (Fossomatic 5000, Foss System). Subsamples of milk were immediately stored at $-20^{\circ} \mathrm{C}$ and analyzed for calcium and phosphorus contents (spectrometry), casein content (infrared spectrophotometry), and color as described by VerdierMetz et al. (1998). The milk lipoprotein lipase activity was measured using an artificial emulsion containing ${ }^{3} \mathrm{H}$ triolein emulsion (Faulconnier et al., 1994). The fatty acid methyl esters in 100-mg samples of lyophilized milk were prepared by direct methylation according to Lerch et al. (2015). The fat globule size distribution was measured by laser light scattering (Mastersizer 2000, Malvern, UK) as detailed in Lopez et al. (2014).

Cheese. Cheese core $\mathrm{pH}, \mathrm{DM}$ and fat contents, and color were determined as described by Verdier-Metz et al. (2000), chloride, calcium, and phosphorus contents as described by Lucas et al. (2006a), and total nitrogen, water-soluble nitrogen, and phosphotungstic acidsoluble nitrogen were measured at 2 stages of ripening (90 and $150 \mathrm{~d}$ ) using the methods described by Ardö (1999). The rheological method used was uniaxial com- pression at a constant displacement rate, as described by Coppa et al. (2011a). Water activity was determined at $25^{\circ} \mathrm{C}$ with a LabMaster (Novasina, Lachen, Switzerland). The FA compositions of the cheese core (at 3, $15,30,90$, and $150 \mathrm{~d}$ of ripening) and rind (at $150 \mathrm{~d}$ of ripening) were determined in 100-mg samples of lyophilized and ground cheeses, as described by Lerch et al. (2015), with one modification concerning the extraction solvent, methanol: $\mathrm{HCl}(95: 5, \mathrm{vol} / \mathrm{vol})$ being replaced by methanol:boron trifluoride (95:5, vol/vol).

\section{Volatile Compounds, VFA, and Free Fatty Acids}

Volatile compounds were determined using purgeand-trap extraction coupled with GC-MS. After the removal of $5 \mathrm{~mm}$ of rind, $5 \mathrm{~g}$ of ripened cheese was homogenized in $50 \mathrm{~mL}$ of ultra-high quality-water by using an Ultra-Turrax homogenizer (IKA Werke GmbH, Staufen, Germany). The analysis was performed on $10 \mathrm{~mL}$ of this suspension as described by Di Cagno et al. (2014). The levels of milk volatile compounds were expressed as $\log _{10}$ of the peak area. Volatile fatty acids were solvent-extracted and saponified from $15 \mathrm{~g}$ of ripened cheese, and then separated and quantified by GC according to Di Cagno et al. (2007). The short- and long-chain free FA (FFA) from $1 \mathrm{~g}$ of ripened cheese core and rind were quantified by capillary GC according to De Jong and Badings (1990).

\section{Microbiological Analyses}

Milk and cheese samples were stored at $-20^{\circ} \mathrm{C}$ until analysis. Presumed microbial groups in milk and cheese were counted on media under the conditions described in Frétin et al. (2017), at different stages of ripening (milk, and at 2, 3, 15, 30, 90, and $150 \mathrm{~d}$ ). Ten grams of cheese (or $10 \mathrm{~mL}$ of milk) was added to $90 \mathrm{~mL}$ of phosphate buffer, $\mathrm{pH}$ 7.5. Milk and cheese samples were homogenized for 2 and 4 min, respectively, in a Stomacher Laboratory Blender (Interscience, St. Nom la Bretèche, France). All microbiological analyses were performed in duplicate.

\section{Sensory Analysis}

The sensory properties of ripened cheeses were evaluated by a panel of 10 trained assessors. Before the evaluation sessions, 2 training sessions were conducted to associate definitions for each attribute. The performance of the panel was validated during the training sessions to control repeatability, discrimination capacity, and consensus. The 35 sensory attributes were initially defined to describe Cantal-type cheeses 
according to Frétin et al. (2017): 7 for appearance, 5 for texture, 9 for odor, 9 for aroma, and 5 for taste. To evaluate appearance attributes, a slice approximately $2 \mathrm{~cm}$ thick was cut from each cheese and presented to the panelists. For other attributes, only the cheese core (a portion weighing $30 \mathrm{~g}$ ) was presented to the panel. The cheeses were placed on a plastic plate, identified by 3 -digit code, and served at room temperature $(20 \pm$ $\left.1^{\circ} \mathrm{C}\right)$. Ten-centimeter unstructured line scales were used to evaluate each attribute, anchored from 0 (no perception) to 10 (very intense perception). The samples were presented in a monadic sequence and distributed according to a Williams Latin square design to take into account the first effect of order and carry-over (Macfie et al., 1989). Overall, two 1-h evaluation sessions were necessary to analyze all the cheeses. Data were collected with the Tastel software (version 2011; ABT Informatique, Rouvroy-sur-Marne, France).

\section{Statistical Analysis}

Statistical analyses were performed with $\mathrm{R}$ for Windows (version 3.3.1; https://www.r-project.org/). The effect of the origin of cream in the milks and cheeses was analyzed using Student's $t$-test. When the homogeneity of variance was considered false, the Welch $t$-test was performed. Fat composition, microbial group levels, and proteolysis in the cheese core were analyzed by one-way repeated-measures ANOVA, where the origin of the cream and the time of ripening were used as fixed factors and cheeses as repeated factor. Sensory data were analyzed using a mixed model, where the origin of the cream was the fixed factor and the assessor was the random factor. Significance was declared at $P<0.05$; $P$-values between 0.05 and 0.10 were considered a tendency, whereas $P>0.10$ was considered not significant.

\section{RESULTS}

\section{Milk Characteristics}

The gross composition of milk and the levels of the major microbial groups were not affected by origin of the cream, regardless of the milk treatment (raw or pasteurized, Table 1). The FA profiles of milks varied depending on the origin of the cream. The P-derived raw milks were yellower and less red than M-derived raw milks $(P<0.01)$. The $\mathrm{P}$-derived raw and pasteurized milks had higher concentrations of C18:0 and UFA $(+8.6 \mathrm{~g} / 100 \mathrm{~g} ; P<0.001$; Supplemental Table S1; https: //doi.org/10.3168/jds.2018-15534), including trans-11 C18:1, cis-9 C18:1, C18:3n-3, total CLA, MUFA, and PUFA, than M-derived milk. In contrast, the M-derived raw and pasteurized milks had higher concentrations of SFA $(+9.2 \mathrm{~g} / 100 \mathrm{~g} ; P<0.001)$, including short- and medium-chain FA (C6:0+C8:0+C10:0 and $\mathrm{C} 12: 0+\mathrm{C} 14$ : $0), \mathrm{C} 16: 0$, and $\mathrm{C} 18: 2 \mathrm{n}-6$. The cis-9 C18:1-to-C16:0 ratio was significantly higher $(P<0.001)$ in $\mathrm{P}$-derived than in M-derived milks.

\section{Cheese Characteristics}

No differences were found for cream origin in the gross chemical composition of the cheese, $\mathrm{pH}$, and mineralization, regardless of milk treatment (raw vs. pasteurized; Table 2). Cream origin did not modify proteolysis during ripening, which increased significantly between 90 and $150 \mathrm{~d}$ of ripening (data not shown). The forces necessary to achieve $60 \%$ and maximum sample deformation were lower for P-derived than for $\mathrm{M}$-derived cheeses. The FA profiles of P-derived and Mderived cheeses were very different in both the core and the rind (Supplemental Tables S2, S3, and S4; https:// doi.org/10.3168/jds.2018-15534), as they were for their respective milks. In the cheese core, the FA profiles remained stable from d 3 to 150 in raw- and pasteurized-milk cheeses. For both raw- and pasteurized-milk cheeses, the level of lipolysis was higher in the cheese rind than in the cheese core (on average, 11 vs. $0.3 \%$ ), as was the total concentration of FFA (on average, 86,925 vs. $2,301 \mathrm{mg} / \mathrm{kg}$ of $\mathrm{DM}$ ), whereas no difference in the level of lipolysis or the FFA concentration was observed for cream origin (Table 3). In the cheese rind, the concentrations of 4 individual FFA changed according to cream origin. The rind of P-derived cheeses had higher concentrations of free $\mathrm{C} 18: 0$ and free $\mathrm{C} 18: 3 \mathrm{n}-3$ and lower concentrations of free C14:0 and free C16:0 than the rind of M-derived cheeses. Similar results were observed in curd at $\mathrm{d} 0$ and in cheese core at 150 d of ripening (Supplemental Table S5; https://doi .org/10.3168/jds.2018-15534). One hundred thirty-two volatile compounds belonging to 6 chemical families were identified in the cheeses: esters had the highest number of detected volatile compounds (34), followed by ketones (29), alcohols (24), aldehydes (22), furan (11) and sulfur (10) compounds, and benzene and thiocyanate derivatives (2) (Supplemental Table S6; https: //doi.org/10.3168/jds.2018-15534). The amounts of 7 of these compounds differed depending on cream origin in both raw- and pasteurized-milk cheeses (Figure 1). Levels of pentanal, 1-pentanol, 3-methyl-2-pentanol, 2-ethyl-hexyl acetate, 2-ethyl furan, and methylbenzene were higher, and the level of 8-nonen-2-one was lower in P-derived cheeses than in M-derived cheeses. The levels of the major microbial groups at different stages of ripening were similar between P-derived and 
Table 1. Effect of cream origin (from cows fed either pasture or maize silage) on gross composition, fatty acids (FA), and major microbial groups of raw and pasteurized milks in the vat before the addition of starter ${ }^{1}$

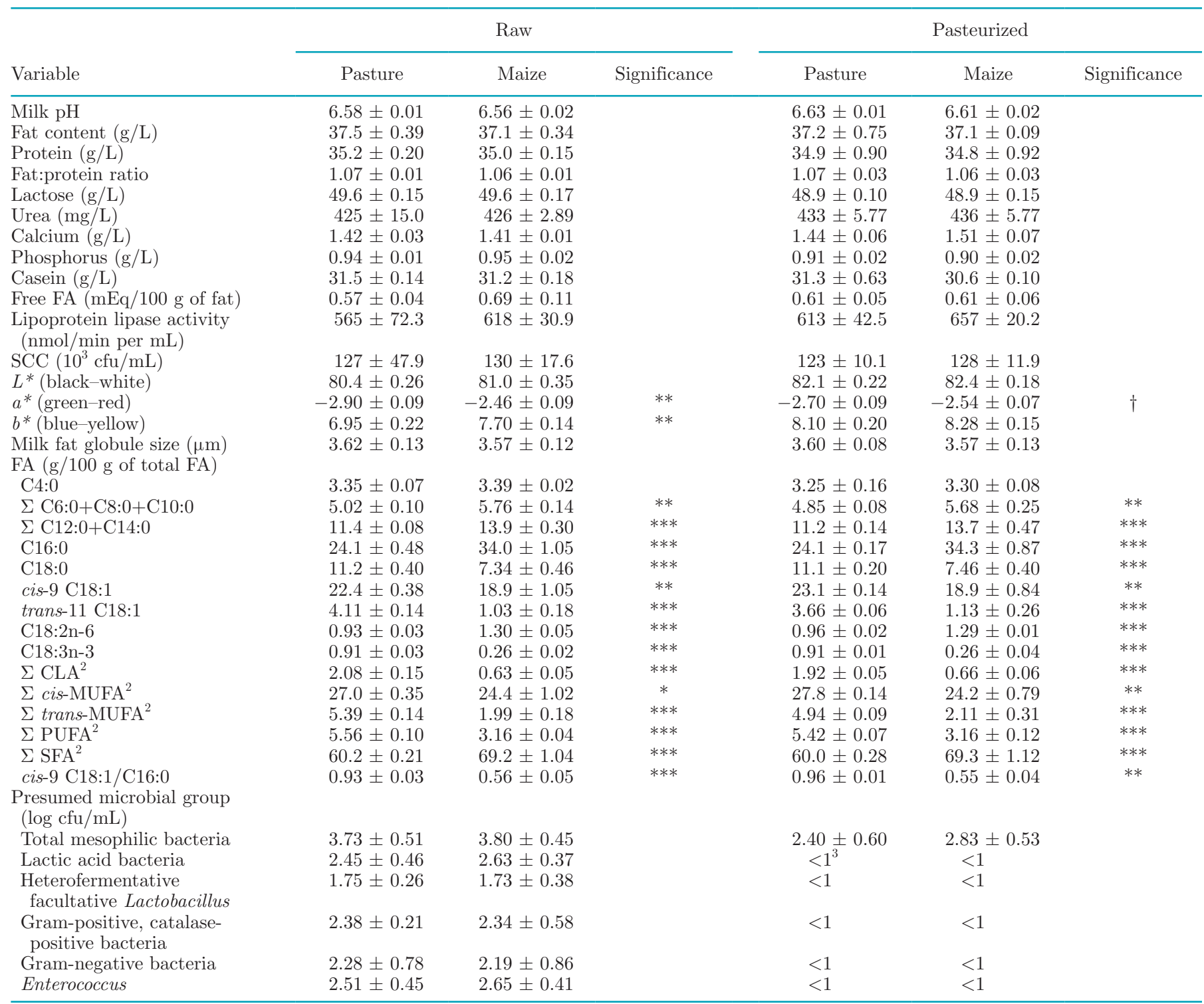

${ }^{1}$ Values reported are the mean from triplicate milk samples $(n=3) \pm \mathrm{SD}$.

${ }^{2}$ Detailed descriptions of the sums of FA are reported in Supplemental File S1 (https://doi.org/10.3168/jds.2018-15534).

${ }^{3}$ Below the detection threshold.

${ }^{* * *} P<0.001 ;{ }^{* *} P<0.01 ;{ }^{*} P<0.05 ; \dagger P<0.10$

M-derived cheeses, in both raw- and pasteurized-milk cheeses (Supplemental Tables S7 and S8; https://doi .org/10.3168/jds.2018-15534). In the cheese core, the levels of microbial groups evolved similarly from d 2 to 150 regardless of milk treatment. Indeed, the level of total mesophilic bacteria including lactic acid bacteria increased mainly on d 3 , remained stable or increased slightly to d 15, and then decreased. The level of grampositive, catalase-positive bacteria increased until d 150. The levels of gram-negative Pseudomonas and
Enterococcus remained stable. The highest levels of gram-positive, catalase-positive bacteria, yeasts, and molds were counted on cheese rind.

In raw-milk cheeses, the amounts of 10 volatile compounds was affected by cream origin (Figure 1). Levels of butanal, heptanal, and 4-methyl-2-pentanol were higher in P-derived cheeses than in M-derived cheeses, whereas those of methanol, 2-propanol, 2-pentanol, 2-heptanol, methyl butanoate, methyl hexanoate, and methyl octanoate were lower. 
Table 2. Effect of cream origin (from cows fed either pasture or maize silage) on gross composition, proteolysis, rheology, and color of raw and pasteurized milk cheeses at $150 \mathrm{~d}$ of ripening ${ }^{1}$

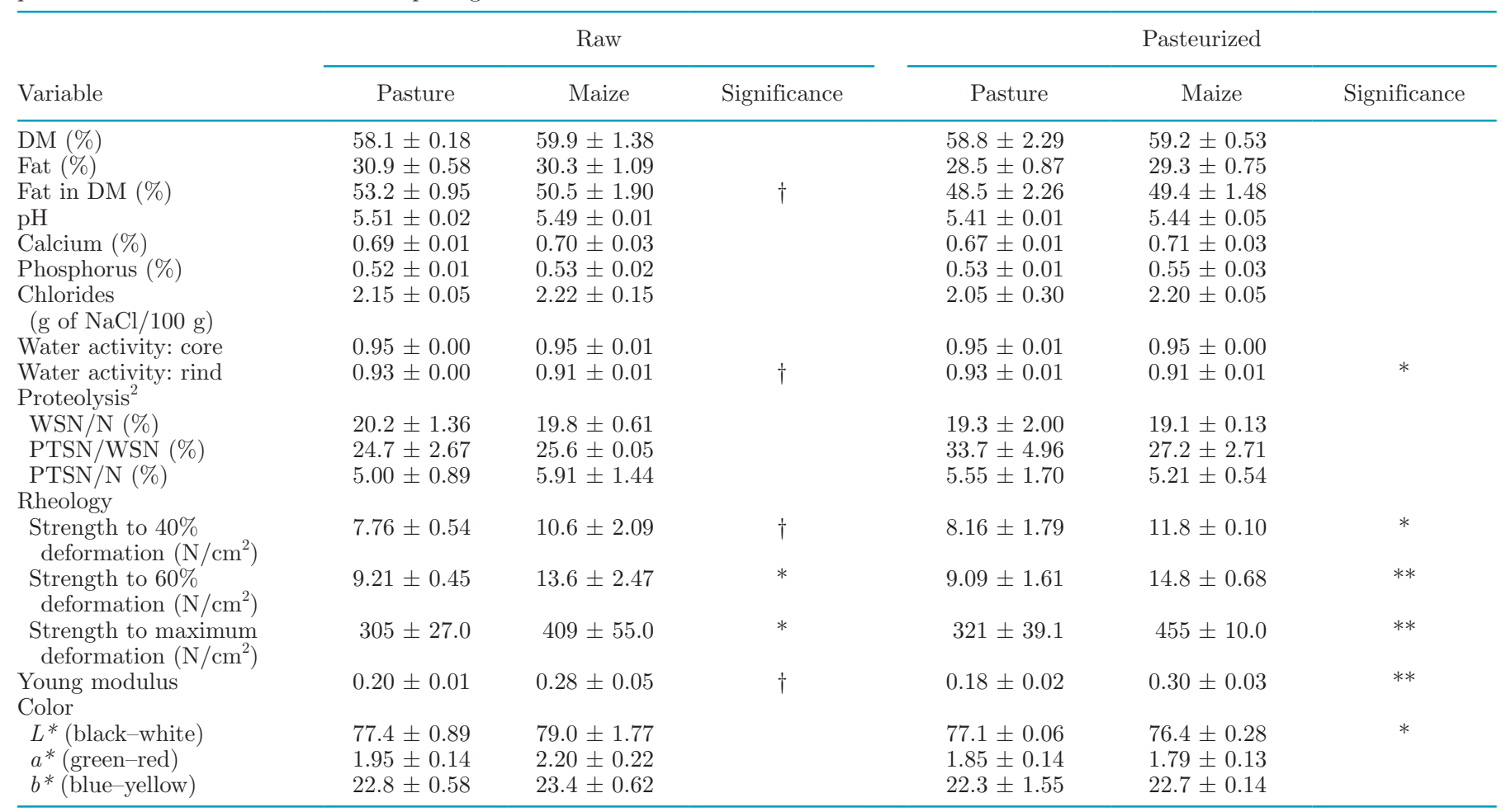

${ }^{1}$ Values reported are the mean from triplicate cheese samples $(\mathrm{n}=3) \pm \mathrm{SD}$.

${ }^{2} \mathrm{WSN}=$ water-soluble nitrogen; PTSN $=$ phosphotungstic acid soluble nitrogen.

${ }^{*} P<0.01 ;{ }^{*} P<0.05 ; \dagger P<0.10$.

Table 3. Effect of cream origin (cows fed either pasture or maize silage) on concentration of free fatty acids (FFA) and percentage of lipolysis in rind and core of raw and pasteurized milk cheeses at $150 \mathrm{~d}$ of ripening

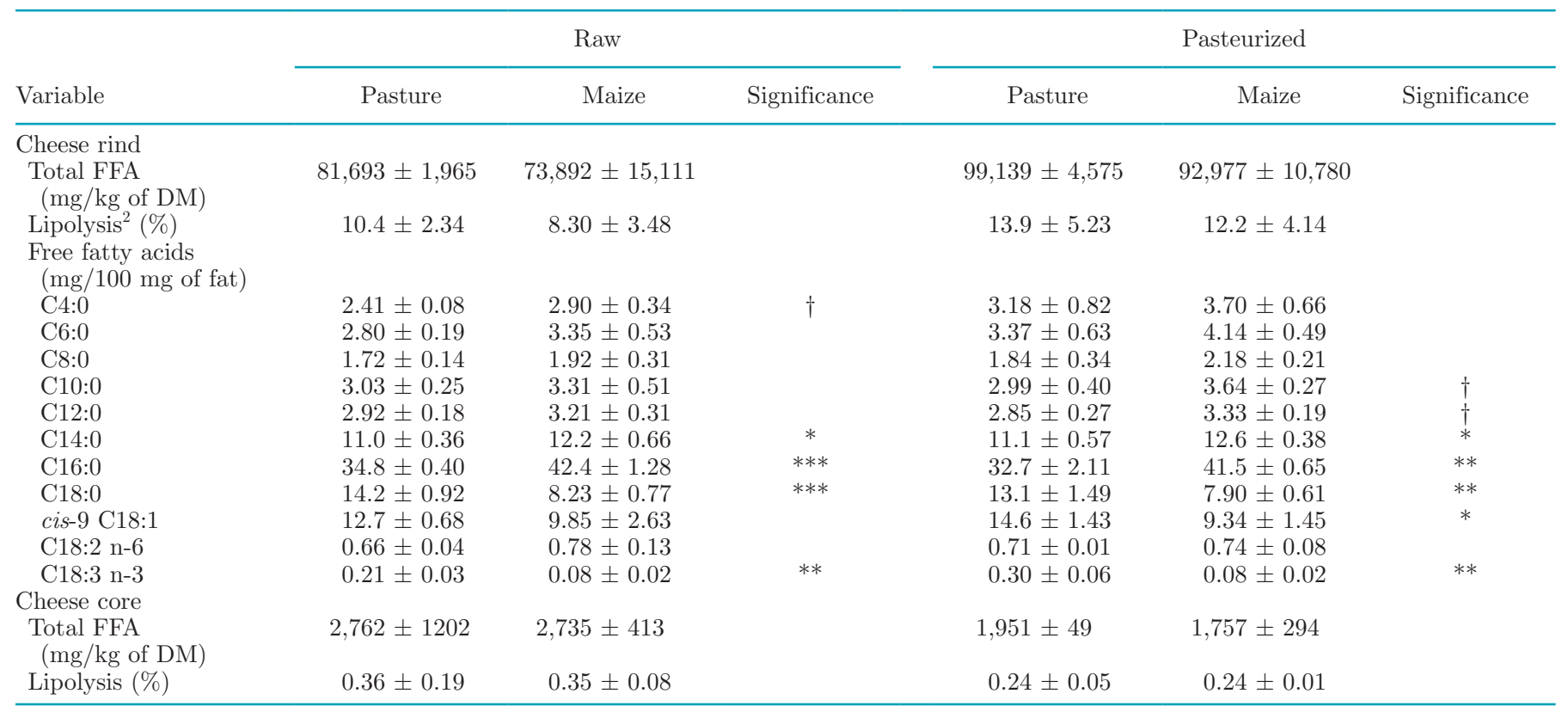

${ }^{1}$ Values reported are the mean from triplicate cheese samples $(\mathrm{n}=3) \pm \mathrm{SD}$.

${ }^{2}$ Lipolysis $(\%)=\{[\mathrm{FFA}]($ expressed in \% of fat) $/$ fat $($ expressed in $\mathrm{mg})\} \times 100$.

*** $P<0.001 ;{ }^{* *} P<0.01 ;{ }^{*} P<0.05 ; \dagger P<0.10$. 
Aldehydes

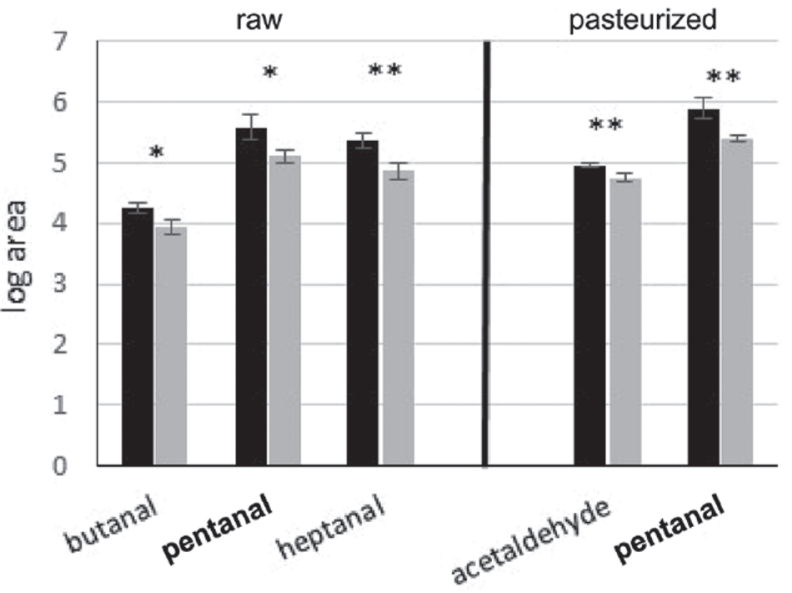

Ketones

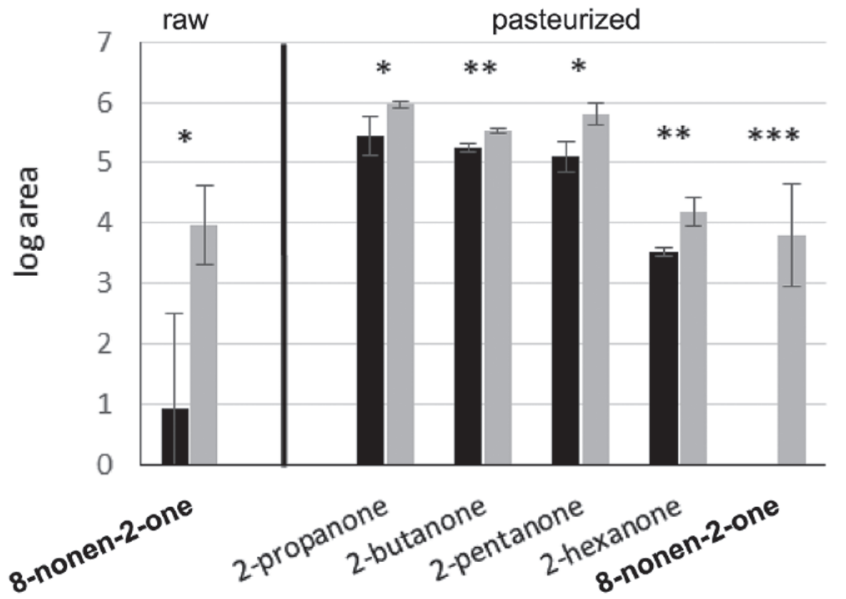

Alcohols

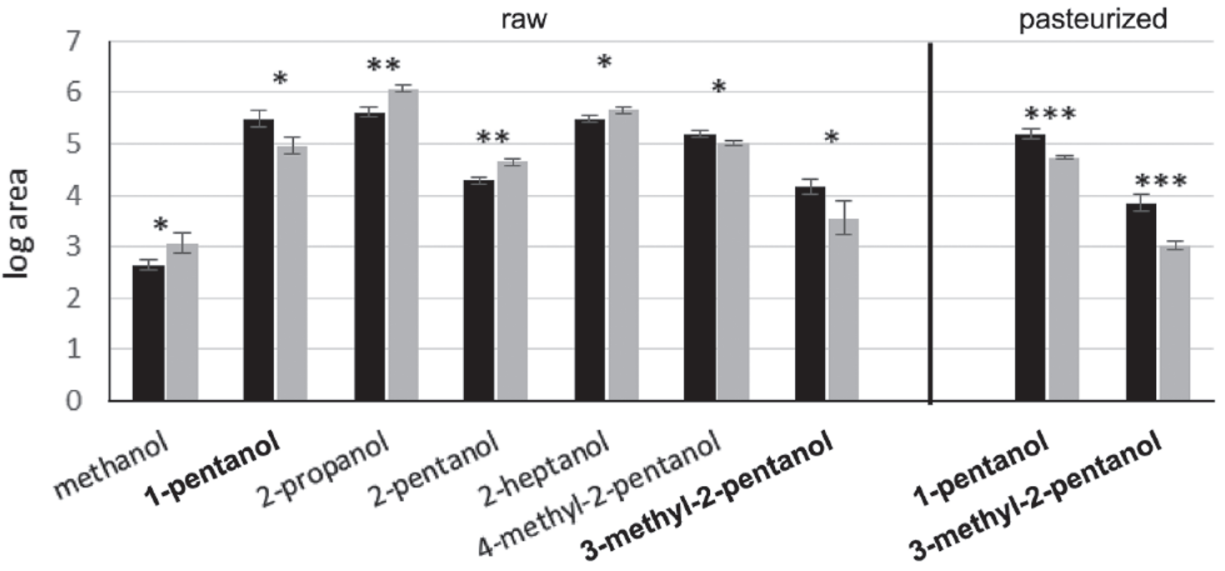

\section{Esters}
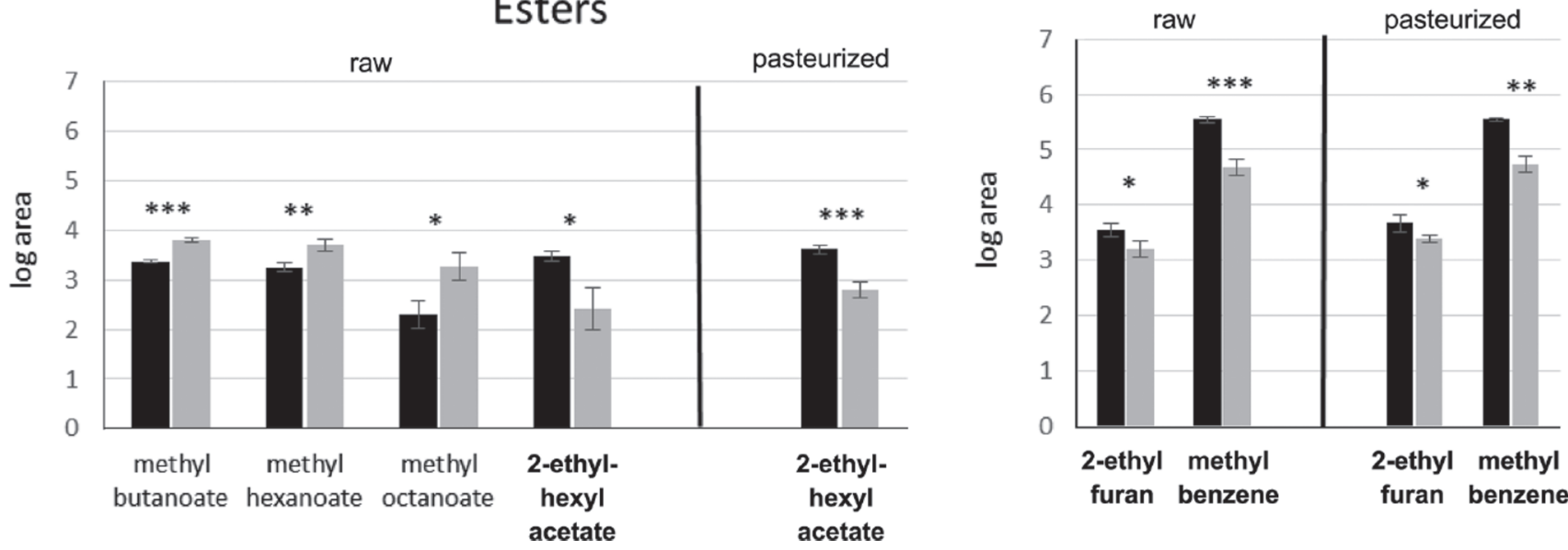

Figure 1. Volatile compounds identified in pasture (black bars) and maize (gray bars) cheeses for which cream origin (from cows on pasture or fed maize silage) had a significant effect according to the Student's $t$-test $\left(* * * P<0.001,{ }^{* *} P<0.01,{ }^{*} P<0.1\right)$. Values reported are means from triplicate cheese samples $(\mathrm{n}=3) \pm \mathrm{SD}$. For several volatile compounds (bolded names), the effect of cream origin was significant in cheeses made from both raw and pasteurized milks. A detailed description of the volatile compounds quantified in cheeses are reported in Supplemental Table S6 (https://doi.org/10.3168/jds.2018-15534). 
In pasteurized-milk cheeses, water activity was slightly higher on $\mathrm{P}$-derived than on $\mathrm{M}$-derived cheese rind $(P<0.05$; Table 2$)$. The color of $\mathrm{P}$-derived cheese core was lighter than that of M-derived cheese core $(P<0.05)$. The concentration of free cis-9 C18:1 was 1.6-fold higher on $\mathrm{P}$-derived rind cheeses than on Mderived rind cheeses $(P<0.01$; Table 3$)$. In the volatile fraction, the concentrations of isobutyric and isovaleric acids were lower in P-derived cheeses than in M-derived cheeses $(P<0.05$; Supplemental Table S9; https://doi .org/10.3168/jds.2018-15534). Five other volatile compounds were affected by the origin of the cream. The level of acetaldehyde was higher and those of 2-propanone, 2-butanoate, 2-pentanone, and 2-hexanone were lower in P-derived than in M-derived cheeses (Figure 1).

\section{Cheese Sensory Properties}

The texture of P-derived cheeses was more elastic, less firm to the touch, and creamier in the mouth compared with M-derived cheeses, regardless of milk treatment (Table 4). The P-derived cheeses were also characterized by a yellower core $(P<0.05)$. In the rind of P-derived raw-milk cheeses, the spot salience (representing the prominence of the relief on the cheese rind) and quantity were scored lower than those of M-derived cheeses $(-1.02$ and -0.82 , respectively; $P<0.01)$. In raw-milk cheeses, "rancid" aroma was lower for P-derived than for M-derived cheeses $(-0.54$; $P<0.05)$. The $\mathrm{P}$-derived pasteurized-milk cheeses were considered by the panelists to be more adhesive and less granular than M-derived cheeses $(+1.19$ and -1.24 , respectively). The latter had a more marbled core $(+0.9 ; P<0.05)$. The M-derived pasteurized-milk cheeses also developed a saltier taste than P-derived cheeses $(+0.43 ; P<0.05)$. In pasteurized-milk cheeses, sensory attributes related to appearance of cheese rind, odor, and aroma were not affected by cream origin.

\section{DISCUSSION}

\section{Milk Composition}

The originality of this study is that uncooked pressed Cantal-type cheeses were manufactured from the same skim milk (identical chemical and microbial composition) and 2 pasteurized creams of different fat compositions. Creams were obtained from cows fed either pasture or maize silage to determine the specific influence of milk fat composition on the sensory properties of cheeses.

The effect of the origin of the cream (P-derived or Mderived) on the milk FA profile was consistent with the literature (Chilliard et al., 2001; Couvreur et al., 2006; Ferlay et al., 2017). Indeed, the UFA concentration was higher in raw and pasteurized milks with P-derived cream (on average, $+8.6 \mathrm{~g} / 100 \mathrm{~g}$ of total FA) than in milks with M-derived cream, as previously reported by Ferlay et al. (2006). Grazing decreased the SFA concentration (C16:0 and short- and medium-chain FA) in milks, and increased UFA (cis-9 C18:1, C18: 3n-3, and total CLA). This result can be explained by the higher intake of C18:3n-3 from grazed grass, for which some intermediates are formed during ruminal biohydrogenation, which could inhibit the de novo synthesis of short-chain FA and a part of C16:0 (Chilliard et al., 2007; Ferlay et al., 2017). Nevertheless, in our study, the milk C18:3n-3 concentration with P-derived cream remained moderate (on average, $0.9 \mathrm{~g} / 100 \mathrm{~g}$ of FA) compared with values reported in other trials on diversified mountain pastures (Ferlay et al., 2006; Coppa et al., 2015). This could result from the lesser botanical diversity and late vegetative stage of these grasslands and from the distribution of concentrates to cows, which could reduce the effect of grazed grass, as reported by Coppa et al. (2015). The FA profiles of cheeses reflected those of milks, as previously reported by Lucas et al. (2006b). However, milk fat globule size did not change with the origin of the cream, although several authors have reported that cow diet changes fat globule size (Couvreur et al., 2007; Lopez et al., 2008; Lopez, 2011). The skimming process eliminated the smallest fat globules, and the standardization of fat content $(37 \mathrm{~g} / \mathrm{L})$ between milks probably helped reduce the differences between milks.

In our experiment, we verified that gross biochemical composition (except FA) and microbial composition were similar between P-derived and M-derived milks, regardless of the milk treatment (raw or pasteurized). In ripened cheeses made from those milks, the origin of the cream had little influence on gross biochemical composition, proteolysis, or levels of the major microbial groups, in agreement with Buchin et al., (1998), in which the cream of milks from a hay- or pasture-based diet was mixed with skim milk from both origins to make uncooked pressed cheeses.

\section{Texture}

The significant differences in texture between $\mathrm{P}$ derived and M-derived cheeses confirmed the major role of milk fat composition in cheese texture (Martin et al., 2005; Coppa et al., 2011). An effect of cow diet on cheese texture through the milk fat composition has been reported previously. However, its effect was more or less important depending on the type of cheeses (Hurtaud et al., 2002; Verdier-Metz et al., 2005). In our 
study, the texture of P-derived cheeses was less firm, more elastic, and creamier, in agreement with their higher cis-9 C18:1-to-C16:0 ratio. These FA are the major UFA and SFA, respectively, and have low and high melting points, respectively (Martin et al., 2005), explaining the texture of $\mathrm{P}$-derived cheeses. The differences in cheese texture were strongly linked to milk fat composition because the other factors (DM content, fat content, proteolysis, and mineralization), which are known to be highly involved in cheese texture (Fox and McSweeney, 2004), did not vary according to the origin of the cream.

\section{Core Color}

The core color, measured by sensory analysis, of Pderived cheeses was slightly yellower than that of Mderived cheeses, as previously reported by Martin et al. (2005). Surprisingly, this difference, conventionally observed by the sensory analysis of cheeses, was not confirmed by spectrometry. In previous studies, the yellow color was considered to be related to a higher concentration of carotenoids (fat-soluble pigments) in pasture-derived cheeses. These pigments originate directly from the cow diet, and fresh grass is much richer

Table 4. Effect of cream origin (cows fed either pasture or maize silage) on sensory characteristics (score from 1 to 10 ) of raw and pasteurized milk Cantal-type cheeses at $150 \mathrm{~d}$ of ripening

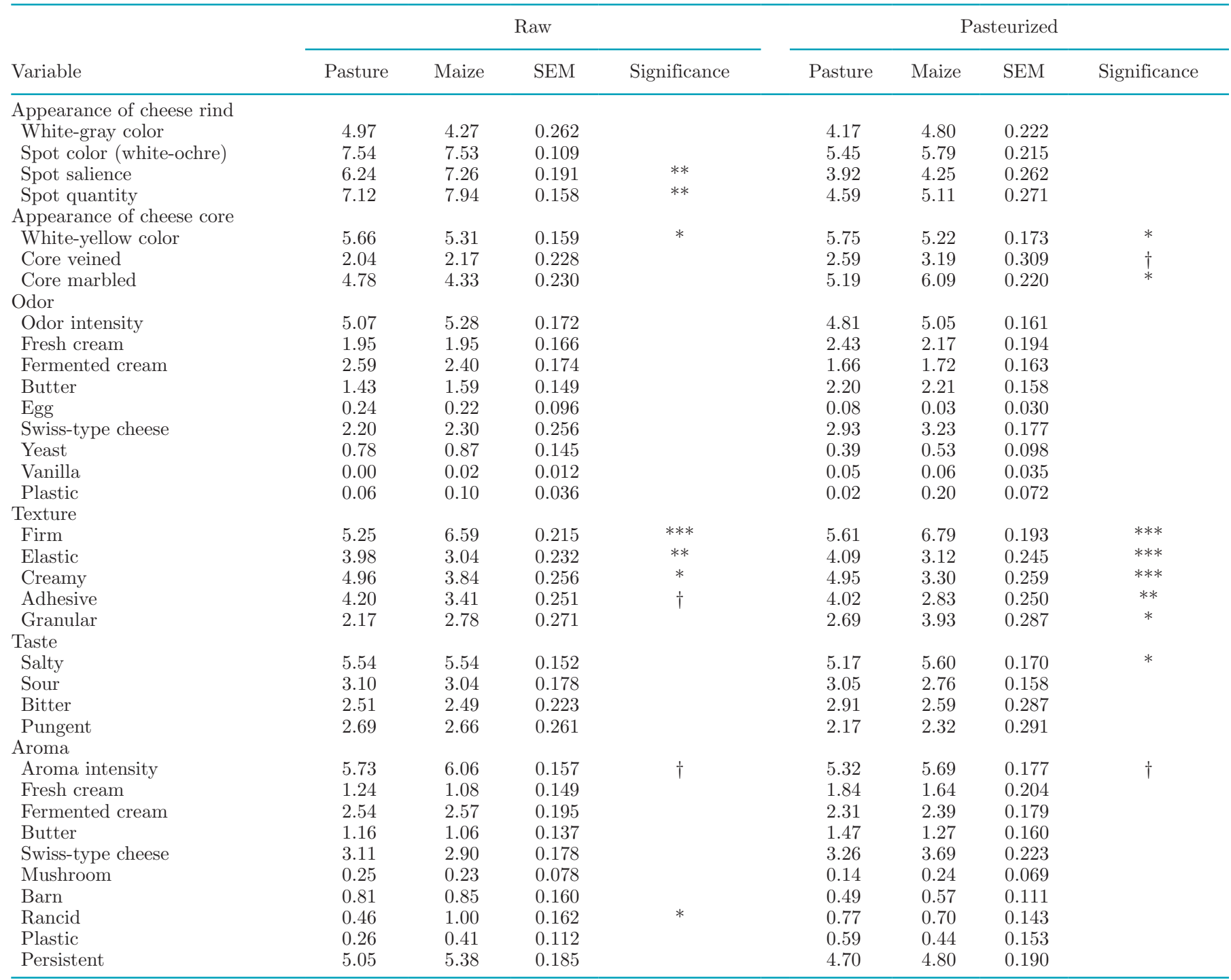

${ }^{1}$ Values reported are means from triplicate cheese samples $(\mathrm{n}=3)$.

${ }^{* * *} P<0.001 ; * * P<0.01 ;{ }^{*} P<0.05 ; \dagger P<0.10$. 
in $\beta$-carotene than maize silage (Nozière et al., 2006). In our study, where only the origin of the cream varied, we noticed that the difference of color between these 2 types of diet was less than usually observed. This suggests that non-fat-soluble constituents such as riboflavin, which would be present in the skim-milk fraction, could also contribute to the color of cheese cores. The first results concerning the variation of this vitamin according to cow diet showed that its content was higher in milks from pasture than in those from maize silage (Laverroux et al., 2014). However, we made all of our cheeses with the same skim milk, which might have reduced the color differences. It is also possible that heating $\left(70^{\circ} \mathrm{C}, 30 \mathrm{~min}\right)$ the P-derived and M-derived creams could reduce the color differences measured afterward in milks by inducing a slight oxidation of cream or browning due to the Maillard reaction, as suggested by Frétin et al. (2017).

\section{Flavor}

Most studies that have compared cheeses and butter obtained with milks from grazing cows or cows fed maize silage- or conserved grass-based diets indicate significant differences in terms of odor, aroma, and taste (Coulon et al., 2004; Martin et al., 2005). In these earlier studies, maize silage led to cheeses and butter with less intense and less diversified flavors. Some authors have hypothesized that milk fat composition plays a key role in the development of cheese flavor. With our experimental design, which allowed us to exclude milk microbiota variations potentially associated with cow diet, we showed that milk fat composition played a minor role in cheese flavor. In contrast, the diversity and the activities of the milk microbial community originating from the farm environment seem to determine cheese flavor. The microbiota of cheese core will contribute more widely to cheese flavor in Cantaltype cheeses than in other, smaller, cheese types (Verdier-Metz et al., 2005). In our trial, odor and aroma of cheeses made with creams of different origins were very similar. This perception of panelists was supported by the small number of volatile compounds with a perceptible threshold, which varied significantly in ripened cheeses (22 out of 132 identified volatile compounds and 2 VFA). In addition, among these compounds, only 8 have previously been identified as odor-active compounds in Cantal-type cheese (Cornu et al., 2009): isobutyric and isovaleric acids, butanal, pentanal, heptanal, 2-butanone, 2-propanol, methylbenzene (also known as toluene). However, most of the 8 compounds previously identified derive from the catabolism of FA (Collins et al., 2003), which presumes that milk fat composition has a major effect on the level of these compounds. The aldehydes (acetaldehyde, butanal, pentanal, and heptanal), the primary alcohol 1-pentanol, and 2-ethyl-furan, which were more abundant in Pderived than in M-derived cheeses, may come from the oxidation of UFA present at higher concentrations in P-derived milk (McSweeney and Sousa, 2000; Bugaud et al., 2001). In contrast, several ketones (2-propanone, 2-butanone, 2-pentanone, 2-hexanone, and 8-nonen2-one) and secondary alcohols (2-propanol, 2-pentanol, 2-heptanol) were less abundant in P-derived than in Mderived cheeses, as a result of oxidation of SFA, which are more concentrated in M-derived milk. Last, the 2 acids affected by diet were not of FA origin but came from catabolism of AA. The balance of ketones and secondary alcohols between raw and pasteurized cheeses has previously been observed and can be explained by the reduction of ketones to alcohols by the raw milk microbiota. Similarly, the distribution of methyl esters in raw milk cheeses can be related to the distribution of their precursor methanol, the esterification reaction being favored by both the concentration of precursors and by raw milk microbiota (Buchin et al., 1998; Beuvier and Buchin, 2004). The modifications of the volatile compound profile via the diet were too few to affect flavor and were observed mostly in raw-milk cheeses. Interesting interactions seem to occur between rawmilk microbiota and fat composition in the formation of volatile compounds. However, considering the cheese microbiota in terms of the level of the main microbial groups, none was modified by the origin of the cream and thus by milk fat composition.

\section{Appearance of Raw-Milk Cheeses}

The P-derived and M-derived pasteurized-milk cheeses had rind of similar appearance. Conversely, focusing on raw-milk cheeses, sensory analysis highlighted lower spot quantity and salience (representing prominence of the relief on the cheese rind) on the rinds of P-derived milk cheeses than on those of M-derived milk cheeses. The lipolysis in the core of raw-milk cheese was limited $(<2 \%)$, in agreement with other studies on uncooked pressed cheeses (Collins et al., 2003) and cooked pressed cheeses (Chamba and Perreard, 2002). Lipolysis was much higher in the cheese rind $(>10 \%)$, comparable to that of mold-ripened cheeses such as Camembert (Collins et al., 2003). Given the level of lipolysis, the total concentration of FFA was 28-fold higher in cheese rind than in the cheese core. The average total concentration of FFA $(77,790 \mathrm{mg} / \mathrm{kg})$ in cheese rind was higher than values published in the international literature for uncooked pressed cheeses and even for other varieties 
of cheeses (Collins et al., 2003), although rind FFA are very rarely analyzed. These new results on cheese rind support our hypothesis that FFA released during lipolysis could have an antimicrobial effect on the rind microbiota. The contents of free C18:0 and free C18: 3n-3 were 1.7- and 2.6-fold higher, respectively, on the rind of P-derived than on the rind of M-derived cheeses. The antimicrobial properties of long-chain unsaturated and medium-chain saturated FFA were demonstrated in vitro several decades ago (Nieman, 1954; Kabara, 1984). Those authors demonstrated that the inhibitory properties of FFA on microbial growth depended on their structure (degree of saturation, length, number of double bonds) and on bacterial species. Coppa et al. (2011a) suggested that the thinner rind of Cantal-type cheeses with a milk fat rich in UFA (e.g., PUFA and cis-9 C18:1) could result from a loss of butter-oil deposited on the cheese rind, creating an environment less favorable to the development of the inoculated mold involved in spot development on the rind of Cantaltype cheeses. Their hypothesis does not seem to be confirmed by our study because the exudation was not higher in raw milk cheeses than in pasteurized milk cheeses. No difference in appearance was noticed on the rind of pasteurized milk cheeses, which suggests that fat composition might modulate the interactions between endogenous milk microorganisms and ripening starters in raw milk cheeses. However, the rind microbiota (including both the endogenous and starter microorganisms) varies widely with cheese type, which could induce differential responses to FFA depending on the type of cheeses studied. Also, the higher the lipolysis of the rind, the greater the expected effect on rind appearance. When the level of lipolysis was very low, as in the core of Cantal-type cheeses, FFA and therefore milk fat composition did not affect cheese flavor. In blue cheese varieties with high levels of lipolysis, FFA and, therefore, milk fat composition could induce significant changes in flavor development (Collins et al., 2003). By culturing the microorganisms on selective media, we observed that the levels of major microbial groups in rind were similar between $\mathrm{P}$-derived and M-derived cheeses. The conventional culture-based approach leads to an underestimation of the diversity of microbial community. For this reason, culture-independent methods based on DNA or RNA sequence analysis are essential to identify the uncultivable microorganisms of the microbial community as well as those that are metabolically active. The next step in understanding the effects of milk fat composition on cheese rind will involve investigation of microbiota taxonomic composition and dynamics, which may be achieved using appropriate metagenomic approaches.

\section{CONCLUSIONS}

Our results deepen the understanding of the role of cow diet in the development of sensory properties of cheeses. We identified the role of the milk fat composition in the appearance of raw-milk cheese rind for the first time. We hypothesize that some FFA with different concentrations depending on the origin of milk fat may have an antimicrobial effect on microorganisms involved in the formation of cheese rind. In our study, the flavor did not differ between the 2 types of cheeses, in contrast to studies that have reported differences between cheeses made from pasture and maize silage. Thus, our results indicate that milk fat composition is not always involved in cheese flavor. Other diet-dependent factors linked to milk biochemical or microbial composition may be involved in the flavor development of cheeses.

\section{ACKNOWLEDGMENTS}

Financial support for this study was provided by the Auvergne region and FEDER funds in the framework of a CPER T2ANSH 2013 project no. 2101088272 SyEL-inAuv (Systemes d'Elevage laitier innovants en Auvergne; France). The authors thank the staff of the INRA Herbipôle farm at Marcenat for animal care, Christelle Lopez (INRA, UMR1253 Science et Technologie du Lait et de l'Oeuf) for fat globule measurements, Isabelle Constant (INRA, UMR1213 Herbivores) for physicochemical analyses on cheeses, Carole Delavaud (INRA, UMR1213 Herbivores) and Cyril Labonne (INRA, UMR1213 Herbivores) for their valuable help in the analyses, and Delphine Pereira (INRA student) for microbial analyses.

\section{REFERENCES}

Ardö, Y. 1999. Evaluating proteolysis by analysing the N content of cheese fractions. Bull. Int. Dairy Fed. 337:4-7.

Beuvier, E., and S. Buchin. 2004. Raw milk cheeses. Pages 319-345 in Cheese: Chemistry, Physics and Microbiology, General Aspects. P. F. Fox, P. L. H. McSweeney, T. M. Cogan, and T. P. Guinee, ed. Academic Press, London, UK.

Buchin, S., V. Delague, G. Duboz, J. L. Berdague, E. Beuvier, S. Pochet, and R. Grappin. 1998. Influence of pasteurization and fat composition of milk on the volatile compounds and flavor characteristics of a semi-hard cheese. J. Dairy Sci. 81:3097-3108. https:/ /doi.org/10.3168/jds.S0022-0302(98)75874-6.

Bugaud, C., S. Buchin, A. Hauwuy, and J. B. Coulon. 2001. Relationships between flavour and chemical composition of Abondance cheese derived from different types of pastures. Lait 81:757-773. https://doi.org/10.1051/lait:2001162.

Callon, C., J. L. Berdagué, E. Dufour, and M. C. Montel. 2005. The effect of raw milk microbial flora on the sensory characteristics of Salers-type cheeses. J. Dairy Sci. 88:3840-3850. https://doi.org/10 .3168/jds.S0022-0302(05)73069-1. 
Chamba, J. F., and E. Perreard. 2002. Contribution of propionic acid bacteria to lipolysis of Emmental cheese. Lait 82:33-44. https:// doi.org/10.1051/lait:2001003.

Chilliard, Y., A. Ferlay, and M. Doreau. 2001. Effect of different types of forages, animal fat or marine oils in cow's diet on milk fat secretion and composition, especially conjugated linoleic acid (CLA) and polyunsaturated fatty acids. Livest. Prod. Sci. 70:31-48. https: //doi.org/10.1016/S0301-6226(01)00196-8.

Chilliard, Y., F. Glasser, A. Ferlay, L. Bernard, J. Rouel, and M. Doreau. 2007. Diet, rumen biohydrogenation and nutritional quality of cow and goat milk fat. Eur. J. Lipid Sci. Technol. 109:828855. https://doi.org/10.1002/ejlt.200700080.

Collins, Y. F., P. L. H. McSweeney, and M. G. Wilkinson. 2003. Lipolysis and free fatty acid catabolism in cheese: A review of current knowledge. Int. Dairy J. 13:841-866. https://doi.org/10.1016/ S0958-6946(03)00109-2.

Coppa, M., A. Ferlay, G. Borreani, A. Revello-Chion, E. Tabacco, G. Tornambé, P. Pradel, and B. Martin. 2015. Effect of phenological stage and proportion of fresh herbage in cow diets on milk fatty acid composition. Anim. Feed Sci. Technol. 208:66-78. https://doi .org/10.1016/j.anifeedsci.2015.07.006.

Coppa, M., A. Ferlay, F. Monsallier, I. Verdier-Metz, P. Pradel, R. Didienne, A. Farruggia, M. C. Montel, and B. Martin. 2011. Milk fatty acid composition and cheese texture and appearance from cows fed hay or different grazing systems on upland pastures. J. Dairy Sci. 94:1132-1145. https://doi.org/10.3168/jds.2010-3510.

Cornu, A., N. Rabiau, N. Kondjoyan, I. Verdier-Metz, P. Pradel, P. Tournayre, J. L. Berdagué, and B. Martin. 2009. Odour-active compound profiles in Cantal-type cheese: Effect of cow diet, milk pasteurization and cheese ripening. Int. Dairy J. 19:588-594. https: //doi.org/10.1016/j.idairyj.2009.04.008.

Coulon, J.-B., A. Delacroix-Buchet, B. Martin, and A. Pirisi. 2004 Relationships between ruminant management and sensory characteristics of cheeses: A review. Lait 84:21. https://doi.org/10.1051/ lait:2004008.

Couvreur, S., C. Hurtaud, C. Lopez, L. Delaby, and J. L. Peyraud 2006. The linear relationship between the proportion of fresh grass in the cow diet, milk fatty acid composition, and butter properties. J. Dairy Sci. 89:1956-1969. https://doi.org/10.3168/jds.S0022 -0302(06)72263-9.

Couvreur, S., C. Hurtaud, P. G. Marnet, P. Faverdin, and J. L. Peyraud. 2007. Composition of milk fat from cows selected for milk fat globule size and offered either fresh pasture or a corn silage-based diet. J. Dairy Sci. 90:392-403. https://doi.org/10.3168/jds.S0022 -0302(07)72640-1.

De Jong, C., and H. T. Badings. 1990. Determination of free fatty acids in milk and cheese procedures for extraction, clean up, and capillary gas chromatographic analysis. J. High Resolut. Chromatogr. 13:94-98. https://doi.org/10.1002/jhrc.1240130204.

Demarigny, Y., E. Beuvier, S. Buchin, S. Pochet, and R. Grappin. 1997. Influence of raw milk microflora on the characteristics of Swiss-type cheeses : II. Biochemical and sensory characteristics. Lait 77:151-167. https://doi.org/10.1051/lait:1997110.

Di Cagno, R., S. Buchin, S. De Candia, M. De Angelis, P. F. Fox, and M. Gobbetti. 2007. Characterization of Italian cheeses ripened under nonconventional conditions. J. Dairy Sci. 90:2689-2704. https: //doi.org/10.3168/jds.2006-654.

Di Cagno, R., I. De Pasquale, M. De Angelis, S. Buchin, C. G. Rizzello, and M. Gobbetti. 2014. Use of microparticulated whey protein concentrate, exopolysaccharide-producing Streptococcus thermophilus, and adjunct cultures for making low-fat Italian Caciotta-type cheese. J. Dairy Sci. 97:72-84. https://doi.org/10.3168/jds.2013 -7078 .

Faulconnier, Y., M. Thévenet, J. Fléchet, and Y. Chilliard. 1994. Lipoprotein lipase and metabolic activities in incubated bovine adipose tissue explants: Effects of insulin, dexamethasone, and fetal bovine serum. J. Anim. Sci. 72:184-191.

Ferlay, A., L. Bernard, A. Meynadier, and C. Malpuech-Brugère. 2017. Production of trans and conjugated fatty acids in dairy ruminants and their putative effects on human health: A review. Biochimie 141:107-120. https://doi.org/10.1016/j.biochi.2017.08.006.
Ferlay, A., B. Martin, P. Pradel, J. B. Coulon, and Y. Chilliard. 2006 Influence of grass-based diets on milk fatty acid composition and milk lipolytic system in Tarentaise and Montbéliarde cow breeds. J. Dairy Sci. 89:4026-4041. https://doi.org/10.3168/jds.S0022 -0302(06)72446-8.

Fox, P. F., and P. L. H. McSweeney. 2004. Cheese: An overview. Pages 1-18 in Cheese: Chemistry, Physics and Microbiology. Vol. 1. P. F. Fox, P. L. H. McSweeney, T. M. Cogan, and T. P. Guinee, ed. Academic Press, London, UK.

Frétin, M., A. Ferlay, I. Verdier-Metz, F. Fournier, M. C. Montel, A. Farruggia, C. Delbès, and B. Martin. 2017. The effects of lowinput grazing systems and milk pasteurisation on the chemical composition, microbial communities, and sensory properties of uncooked pressed cheeses. Int. Dairy J. 64:56-67. https://doi.org/10 .1016/j.idairyj.2016.09.007.

Frétin, M., B. Martin, E. Rifa, I. Verdier-Metz, D. Pomiès, A. Ferlay, M. C. Montel, and C. Delbès. 2018. Bacterial community assembly from cow teat skin to ripened cheeses is influenced by grazing systems. Sci. Rep. 8:200. https://doi.org/10.1038/s41598-017 $-18447-y$.

Hurtaud, C., L. Delaby, J. L. Peyraud, J. L. Durand, J. C. Emile, C. Huyghe, and G. Lemaire. 2002. Evolution of milk composition and butter properties during the transition between winter-feeding and pasture. Pages 574-575 in Multi-Function Grasslands: Quality Forages, Animal Products and Landscapes, 19th General Meeting of the European Grassland Federation, France.

Kabara, J. J. 1984. Antimicrobial agents derived from fatty acids. J. Am. Oil Chem. Soc. 61:397-403. https://doi.org/10.1007/ BF02678802.

Laverroux, S., J. Vallet, C. Chassaing, C. Girard, C. Agabriel, B. Martin, and B. Graulet. 2014. Riboflavin secretion in cow's milk varies according to diet composition and season. Pages 323-326 in Joint Meeting of FAO-CIHEAM Mountain Pastures and Mediterranean Forages Resources Networks and Mountain Cheese Network, Clermont-Ferrand, France.

Lerch, S., A. Ferlay, B. Graulet, C. Cirié, I. Verdier-Metz, M. C. Montel, Y. Chilliard, and B. Martin. 2015. Extruded linseeds, vitamin $\mathrm{E}$ and plant extracts in corn silage-based diets of dairy cows: Effects on sensory properties of raw milk and uncooked pressed cheese. Int. Dairy J. 51:65-74. https://doi.org/10.1016/j.idairyj 2015.07.006

Lopez, C. 2011. Milk fat globules enveloped by their biological membrane: Unique colloidal assemblies with a specific composition and structure. Curr. Opin. Colloid Interface Sci. 16:391-404. https:// doi.org/10.1016/j.cocis.2011.05.007.

Lopez, C., V. Briard-Bion, and O. Ménard. 2014. Polar lipids, sphingomyelin and long-chain unsaturated fatty acids from the milk fat globule membrane are increased in milks produced by cows fed fresh pasture based diet during spring. Food Res. Int. 58:59-68. https://doi.org/10.1016/j.foodres.2014.01.049.

Lopez, C., V. Briard-Bion, O. Menard, F. Rousseau, P. Pradel, and J. M. Besle. 2008. Phospholipid, sphingolipid, and fatty acid compositions of the milk fat globule membrane are modified by diet. J. Agric. Food Chem. 56:5226-5236. https://doi.org/10.1021/ jf7036104.

Lucas, A., C. Agabriel, B. Martin, A. Ferlay, I. Verdier-Metz, J. B. Coulon, and E. Rock. 2006a. Relationships between the conditions of cow's milk production and the contents of components of nutritional interest in raw milk farmhouse cheese. Lait 86:177-202. https://doi.org/10.1051/lait:2005049.

Lucas, A., E. Rock, J. F. Chamba, I. Verdier-Metz, P. Brachet, and J. B. Coulon. 2006b. Respective effects of milk composition and the cheese-making process on cheese compositional variability in components of nutritional interest. Lait 86:21-41. https://doi.org/ 10.1051/lait:2005042.

Macfie, H. J., N. Bratchell, K. Greenhoff, and L. V. Vallis. 1989. Designs to balance the effect of order of presentation and first-order carry-over effects in Hall tests. J. Sens. Stud. 4:129-148. https:// doi.org/10.1111/j.1745-459X.1989.tb00463.x.

Marilley, L., and M. G. Casey. 2004. Flavours of cheese products: Metabolic pathways, analytical tools and identification of produc- 
ing strains. Int. J. Food Microbiol. 90:139-159. https://doi.org/10 .1016/S0168-1605(03)00304-0.

Martin, B., D. Pomiès, P. Pradel, I. Verdier-Metz, and B. Rémond. 2009. Yield and sensory properties of cheese made with milk from Holstein or Montbéliarde cows milked twice or once daily. J. Dairy Sci. 92:4730-4737. https://doi.org/10.3168/jds.2008-1914.

Martin, B., I. Verdier-Metz, S. Buchin, C. Hurtaud, and J. B. Coulon. 2005. How do the nature of forages and pasture diversity influence the sensory quality of dairy livestock products? Anim. Sci. 81:205-212. https://doi.org/10.1079/ASC50800205.

McSweeney, P. L. H., and M. J. Sousa. 2000. Biochemical pathways for the production of flavour compounds in cheeses during ripening: A review. Lait 80:32. https://doi.org/10.1051/lait:2000127.

Nieman, C. 1954. Influence of trace amounts of fatty acids on the growth of microorganisms. Bacteriol. Rev. 18:147-163.

Nozière, P., B. Graulet, A. Lucas, B. Martin, P. Grolier, and M. Doreau. 2006. Carotenoids for ruminants: From forages to dairy products. Anim. Feed Sci. Technol. 131:418-450. https://doi.org/ 10.1016/j.anifeedsci.2006.06.018.

Verdier-Metz, I., B. Martin, S. Hulin, A. Ferlay, P. Pradel, and J. B. Coulon. 2002. Combined influence of cow diet and pasteurisation of the milk on sensory properties of French PDO Cantal cheese. Congrilait 26th IDF World Dairy Congress (ed. CIDIL). CDR, Paris, France.

Verdier-Metz, I., J. B. Coulon, P. Pradel, C. Viallon, H. Albouy, and J. L. Berdagué. 2000. Effect of the botanical composition of hay and casein genetic variants on the chemical and sensory characteristics of ripened Saint-Nectaire type cheeses. Lait 80:361-370. https:// doi.org/10.1051/lait:2000131.

Verdier-Metz, I., J. B. Coulon, P. Pradel, C. Viallon, and J. L. Berdagué. 1998. Effect of forage conservation (hay or silage) and cow breed on the coagulation properties of milks and on the characteristics of ripened cheeses. J. Dairy Res. 65:9-21.

Verdier-Metz, I., G. Gagne, S. Bornes, F. Monsallier, P. Veisseire, C Delbès-Paus, and M. C. Montel. 2012. Cow teat skin, a potential source of diverse microbial populations for cheese production Appl. Environ. Microbiol. 78:326-333. https://doi.org/10.1128/ AEM.06229-11.

Verdier-Metz, I., B. Martin, P. Pradel, H. Albouy, S. Hulin, M.-C. Montel, and J.-B. Coulon. 2005. Effect of grass-silage vs. hay diet on the characteristics of cheese: Interactions with the cheese model. Lait 85:12. https://doi.org/10.1051/lait:2005032. 